\title{
pombalina
}

(8)

\section{Reflexões camonianas}

Autor(es): $\quad$ Ramalho, Américo da Costa

Publicado por: Imprensa da Universidade de Coimbra

URL persistente:

URI:http://hdl.handle.net/10316.2/30748

DOI:

DOI:http://dx.doi.org/10.14195/978-989-26-0569-2_8

Accessed : $\quad$ 26-Apr-2023 16:29:38

A navegação consulta e descarregamento dos títulos inseridos nas Bibliotecas Digitais UC Digitalis, UC Pombalina e UC Impactum, pressupõem a aceitação plena e sem reservas dos Termos e Condições de Uso destas Bibliotecas Digitais, disponíveis em https://digitalis.uc.pt/pt-pt/termos.

Conforme exposto nos referidos Termos e Condições de Uso, o descarregamento de títulos de acesso restrito requer uma licença válida de autorização devendo o utilizador aceder ao(s) documento(s) a partir de um endereço de IP da instituição detentora da supramencionada licença.

Ao utilizador é apenas permitido o descarregamento para uso pessoal, pelo que o emprego do(s) título(s) descarregado(s) para outro fim, designadamente comercial, carece de autorização do respetivo autor ou editor da obra.

Na medida em que todas as obras da UC Digitalis se encontram protegidas pelo Código do Direito de Autor e Direitos Conexos e demais legislação aplicável, toda a cópia, parcial ou total, deste documento, nos casos em que é legalmente admitida, deverá conter ou fazer-se acompanhar por este aviso. 


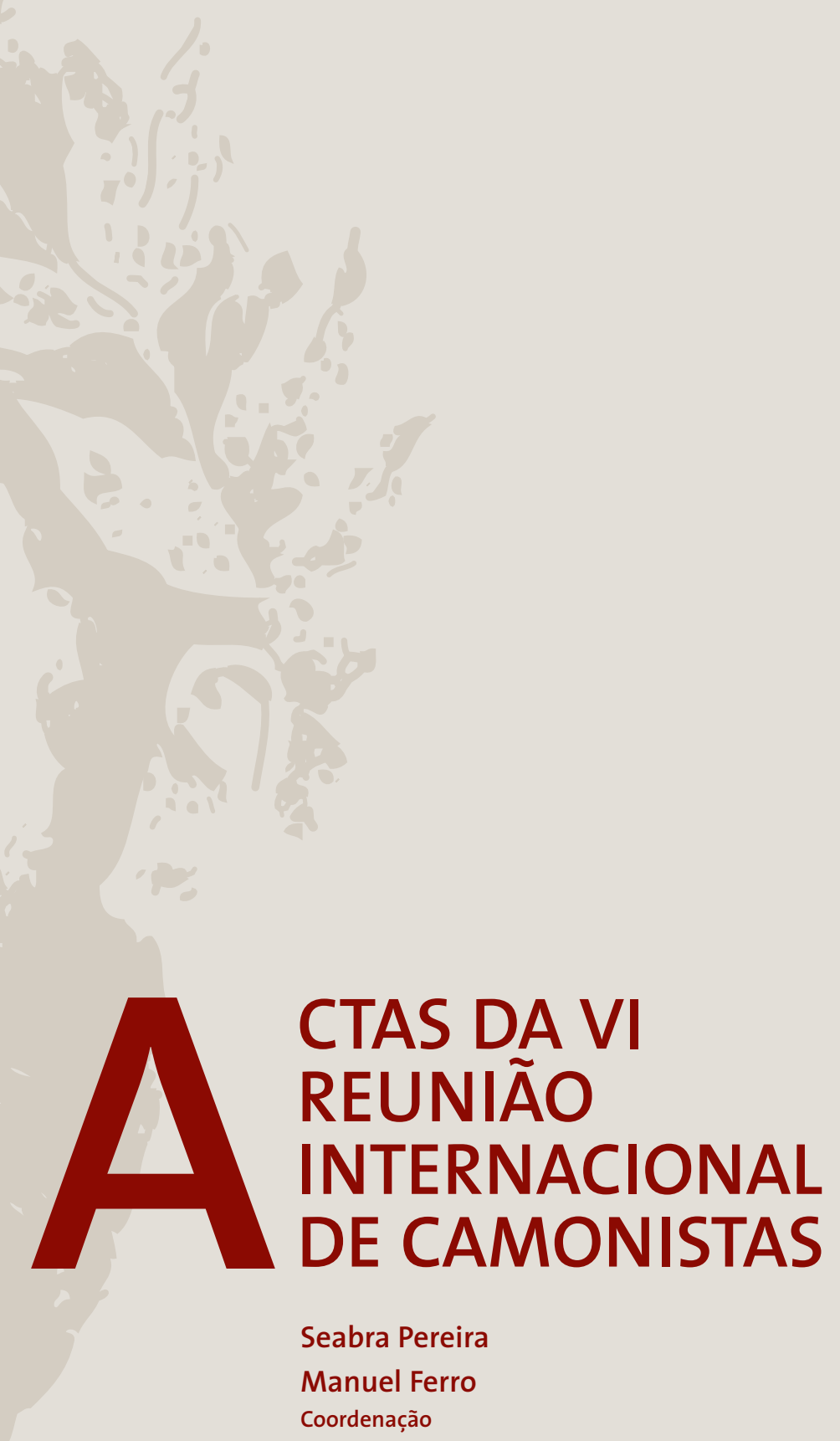




\author{
Américo da Costa Ramalho \\ Universidade de Coimbra
}

\title{
REFLEXÓES CAMONIANAS
}

A primeira das quatro Reflexôes Camonianas que vou ler diz respeito à Vida Ignorada de Camóes do Dr. José Hermano Saraiva, livro que na terceira edição, de 1994, aparece decorado do subtítulo de Uma história que o tempo censurou.

Do ponto de vista cultural, o Dr. Saraiva teve a infelicidade de considerar como um caso típico de nobreza ignorante (e até hoje não alterou a sua posição) um dos fidalgos mais cultivados do Portugal quinhentista: alguém que era familiar com Ovídio e lia Horácio, ambos no original, compunha versos latinos e falava latim.

Interpretando à sua maneira uma anedota ${ }^{1}$, o Dr. Saraiva chega a dizer que o Senhor D. Jorge náo sabia o que era um humanista. Isto apesar de ter sido aluno dum humanista que seu pai, o rei D. Joáo II, mandara vir de Itália para o ensinar.

Mais tarde, o mesmo Dr. Saraiva, num programa de televisão com grande audiência, confundiu D. Jorge, duque de Coimbra, com o duque de Bragança, D. Jaime. Encontrei posteriormente em lugares diversos pessoas que haviam dado pelo erro e que se recordavam de que o autor do programa televisivo nunca o corrigiu.

Já o disse, e repito, que faz muita falta no livro do Dr. Saraiva um índice de nomes próprios que permita mais facilmente verificar as suas afirmaçóes.

$\mathrm{Na}$ Vida Ignorada, o Dr. Saraiva fala duma conspiração de silêncio em volta da personalidade de Camóes, para não ofender a influente família dos Noronhas. Escreve, por exemplo: «Mas, por outro lado, o seu nome recordava tristes histórias e todos os louvores ofendiam uma familia poderosa e as muitas outras familias que com elas se sentiam solidárias.» ( $3^{a}$ edição, p. 480).

Como se explica entáo que Diogo Paiva de Andrade, sobrinho do protagonista desse escândalo, D. Violante de Andrade, e filho de seu irmão Francisco, num parecer publicado à frente dum livro de João Soares de Brito, composto expressamente para exaltar a reputação do poeta, tenha elogiado abertamente Camóes?

Eis o parecer impresso: «Senhor. Neste caderno que V. M. me mandou ver de João Soares de Brito, não achei cousa por onde se lhe possa negar a licença que pede, senão

\footnotetext{
${ }^{1}$ Explicada em Américo da Costa Ramalho, Para a História do Humanismo em Portugal II, Lisboa, Fundação Calouste Gulbenkian / Junta Nacional de Investigação Científica e Tecnológica, 1994, pp. 67-68; e em Camóes no seu tempo e no nosso, Coimbra, Almedina, 1992, pp. 63-66.
} 
muytas porque (sic) se lhe deve conceder, poys a tençâo foy acudir pello merito do nosso insigne poeta Luis de Camóes, obedecendo a quem com zello tão generoso lhe pedio que o defendesse. e obra he feyta con tanta erudição, eloquencia, \& doutrina que ficou o mesmo Poeta em grande obrigação a esta calumnia por lhe fazer alcançar a honra de táo excelente defensão. Lisboa, 10s 26. de Octubro de 1640.

Diogo Paiva d'Andrade."

O livro em defesa de Camôes, cuja publicação Diogo Paiva d'Andrade apoiou, é a Apologia em que defende Ioam Soares de Brito a Poesia do Principe dos Poetas d'Hespanha. Na carta 4 de est. 67 à 75 e cant. 2 est. 21, "హ responde à Censura d'hum Critico d'estes tempos. A Ioam Rodrigues de Sá de Meneses, Cavalleyro da ordem de Santiago, Camareyro-mor d'El Rey D. Ioam IV. N.S. Filho promogenito do Conde de Penaguião, \& herdeiro de sua Casa, etc. Em Lisboa, na officina de Lourenço de Anveres, no Anno de 1641. O I. da Restauração de Portugal.»

Conheço de Diogo de Paiva d'Andrade o poema latino Chauleida (melhor que Chauleidos) sobre o cerco de Chaul de 1593/94, portanto muitos anos depois da morte de Camóes, segundo provou o Lic. ${ }^{\circ}$ António Lopes de Andrade na sua tese de Mestrado ${ }^{2}$. O Dr. Saraiva pensa que se trata do cerco de $1570 / 71$, referido na Década VIII, de Diogo de Couto, onde há umas palavras sobre Camóes. Mas o cerco de 1593/94 vem na Década XI.

Conheço a tragédia $E d u a r d u s^{3}$ sobre a prisão, por influência dos espanhóis, e posterior morte na fortaleza de Milão, em 1649, do irmão de D. João IV, o infante D. Duarte.

Mas a mais conhecida obra de Paiva de Andrade está escrita em português e chamase Casamento Perfeito. Estranha escolha de assunto, que a má-língua não deixaria de assinalar, se sua tia Violante fosse acusada de adultério com Luís de Camóes!

Creio que o Dr. Saraiva ainda não explorou esta pista: com a sua viva imaginação, talvez lá descubra alguma coisa que sirva aos seus propósitos.

Poesia Novilatina

Fidelino de Figueiredo lamentou no seu livro A Épica Portuguesa no Século XVI que os humanistas não tivessem dado importância à Expansão Ultramarina portuguesa, tratando-a em versos latinos. Como já acentuou Sânchez Marín, professor da Universidade de Granada, numa comunicação apresentada ao Congresso Internacional Humanismo Português na Época dos Descobrimentos ${ }^{5}$, realizado em Coimbra, em Outubro de 1991, essa opinião do investigador português é falsa.

E eu poderei acrescentar que os poetas do Humanismo em Portugal, se de alguma coisa podem ser acusados, é exactamente do contrário. Eles podem até ser responsabilizados moralmente, por terem tratado à saciedade certos temas como a

\footnotetext{
2 António Manuel Lopes de Andrade, A 'Chauleida’ de Diogo Paiva de Andrade (canto oitavo). Introdução, tradução e comentário. Dissertação de Mestrado, apresentada à Faculdade de Letras de Coimbra, 1994.

${ }^{3}$ Diogo Paiva de Andrade, A tragédia D. Duarte (Eduardus). Introdução, tradução e notas de José Nuno Pereira Pinto. Lisboa, Imprensa Nacional / Casa da Moeda, 1985.

4 São Paulo, 1987, p. 496.

5 José A. Sánchez Marín, Características de la obra poética de Manuel da Costa, Actas, Coimbra, 1993, pp. 257-274. Nesta comunicação, o seu autor trata do poema DE Nuptiis Eduardi atque Isabellae.
} 
expansão no Norte de África, incitando D. Sebastião, a bem dizer desde que nasceu, a castigar a audácia dos mouros que não se limitavam a atacar os estabelecimentos portugueses no Norte de África, mas tornavam extremamente perigosa a navegação no Mediterrâneo e no Atlântico Norte.

Temos poesia heróica novilatina desde os dias longínquos de Cataldo. Com efeito, o siciliano chegou a Portugal, trazendo na bagagem um poema, Arcitinge, sobre a conquista de Arzila e Tânger por D. Afonso V em 1472. Nesta empresa participou o príncipe herdeiro, o futuro rei D. João II, então com 17 anos de idade. E na intenção do humanista tratava-se exactamente de homenagear D. João II que o convidara a vir trabalhar em Portugal, onde terá chegado em 1485. Uma das finalidades, que o Sículo cumprirá escrupulosamente, será a de ensinar D. Jorge, o filho bastardo do rei, que ele tornou um fidalgo ilustrado, em que pese ao Dr. Saraiva.

$\mathrm{Na}$ Arcitinqe temos um poema heróico em latim sobre a História de Portugal, anterior a qualquer das tentativas épicas do Cancioneiro Geral de Garcia de Resende, publicado em 1516 .

Mostrei já, noutra ocasião, que Cataldo se ocupou de Arcitinqe, antes de vir para Portugal. O seu informador foi possivelmente Fernando Coutinho, futuro bispo de Lamego e Silves, que era então estudante em Itália e interveio na vinda de Cataldo para o nosso País.

Quanto a portugueses com matéria épica tratada em versos latinos, nas composiçôes mais variadas, desde o pequeno epigrama ao longo poema heróico, posso citar Henrique Caiado, Lourenço de Cáceres, André de Resende, Inácio de Morais, Diogo de Teive, Manuel da Costa, Jerónimo Cardoso, Aquiles Estaço, Diogo Pires, António e Miguel de Cabedo e outros mais. Todos eles contribuíram para criar o clima épico em que surgiu Camóes.

Gostaria de ocupar-me aqui livremente de Manuel da Costa, famoso professor de Direito de Coimbra e Salamanca, e bom poeta novilatino, já referido em outros trabalhos meus, e agora tratado, no campo do epitalâmico, em dois artigos de Sánchez Marín ${ }^{6}$. Embora posteriores aos estudos do meu prezado colega e amigo granadino, as considerações que farei são independentes das suas. Aliás, aconselho a leitura de Sánchez Marín que, num jeito narrativo aliciante, conta o argumento dos dois poemas.

Pela minha parte, e dentro do âmbito da presente comunicação, prefiro insistir no aspecto épico.

A palavra epitalâmio, como todos sabem, é um helenismo que tem por base qalamos (leito nupcial). É, portanto, o epitalâmio um género de poema dedicado ao casamento.

$\mathrm{Na}$ tradição greco-latina, havia um modelo célebre dum autor que era lido, estudado e discutido em meados do século XVI entre nós. E também considerado difícil ${ }^{7}$. Refiro-me a Gaio Valério Catulo e ao seu carme LXIV, o epitalâmio de Tétis

\footnotetext{
${ }^{6}$ Para o segundo artigo, ver a nota anterior. O primeiro foi «Um epitalâmio neolatino: el Carmen Proteus de Manuel da Costa" sobre o "In nuptiis Ioannis et Ionnae Carmen", publicado em Miscelânea de Estudos em Honra do Prof. A. Costa Ramalho, Coimbra, Centro de Estudos Clássicos e Humanísticos, 1992, pp. 190-213.

${ }^{7}$ Por exemplo, no Casamento Perfeito de Diogo de Paiva de Andrade. Cf. a edição Sá da Costa, Lisboa, 1944, elaborada por Fidelino de Figueiredo, na p. 72.
} 
e Peleu, um poema mitológico, muito conhecido na época, quer pelo tema, quer pela execução. Com efeito, nele se encontra a prática alexandrina de introduzir no corpo do poema um excursus que produz o efeito do poema dentro do poema. Assim, nas núpcias de Tétis e Peleu os convidados admiram a colcha que cobre o leito nupcial e descreve as aventuras amorosas de outro par mitológico, Teseu e Ariana.

Ora há sinais de que o carme LXIV de Catulo está presente nos dois epitalâmios de Manuel da Costa. São eles o De Nuptiis Eduardi et Isabellae, ao casamento do Infante D. Duarte, irmão mais novo de D. João III, com D. Isabel, filha do duque de Bragança, D. Jaime, falecido, e irmã do duque actual, D. Teodósio. Este casamento realizou-se em 1537.

E o outro, In nuptiis Ioannis et Ioannae, Lusitaniae principum, carmen, ao casamento do príncipe herdeiro D. João, filho de D. João III, com D. Joana, filha do imperador Carlos V, em 1552. São os pais de D. Sebastião, nascido dezoito dias depois da morte do seu progenitor, em 20 de Janeiro de 1554.

O primeiro poema é, como se vê, quinze anos mais antigo que o segundo. Tenho mesmo a impressão de que o segundo poema, aliás muito menos extenso que o primeiro, serviu para perfazer um pequeno volume que Manuel da Costa publicou no ano mesmo dessa união principesca, em 1552.

Em qualquer caso, neste poema ao casamento do herdeiro do trono de Portugal com sua prima, a filha do poderoso imperador, que era também rei de Espanha, os Méritos das duas casas reinantes, a portuguesa e a casa de Áustria, são devidamente postos em relevo nas pessoas dos seus representantes mais qualificados, D. João III e Carlos V ou Carlos I de Espanha.

Proteu, a divindade marinha profética de Os Lusíadas (X, 7), é quem conta às Ninfas as festas que se desenrolam em Lisboa, "cidade que recebeu o nome de Ulisses, e que, com grande esforço, estende o seu poder desde os territórios da Libia até às terras desconhecidas do rico Oriente, graças aos navios dos Lusiadas»:

"sed enim de nomine Vlyssis

Dicta urbs, Lysiadum ratibus quae cuncta subegit

Finibus a Lybicis Orientis usque ad beati

Ignotas terras grandi molimine uires

Explicat..."

A travessia do Tejo, feita pela princesa, do Barreiro para Lisboa, dá ao poeta a ocasião de falar do sogro de Joana, o rei D. João III de Portugal, e dos seus acompanhantes. D. João III é apresentado como um árbitro da civilização, expressa nas trocas comerciais pacíficas. Pelo contrário, o pai da jovem esposa, o imperador Carlos V, aparece como o general vitorioso sobre alemães, mouros e o próprio rei de França a quem aprisionou.

A princesa Joana é mais bela que Tétis quando foi entregue ao rei Peleu, seu marido, e as Náiades, divindades marinhas, oferecem-lhe uma colcha nupcial em que estão representados os ascendentes da família de sua mãe, desde D. Afonso Henriques ao nascimento de D. Joáo III, contemplado com horror pelos tiranos de África e das Índias, mas recebido nos braços da "Aurea Paz, cuja insígnia é a verde oliveira" "uiridente insignis oliua / Aurea Pax». 
O segundo epitalâmio parece menos hierático e mais participado pelo poeta, cujos pais tinham sido súbditos da Casa de Bragança.

Os momentos de epopeia não faltam, quase desde o começo: a noiva, D. Isabel, é filha do glorioso duque D. Jaime "que venceu os africanos, só com lhe ouvirem o nome e, apesar de ausente, fizera tremer as cidades atónitas. A cuja chegada, Azamor se inclinara, abrindo-lhe as portas de par em par, por não se atrever a contemplar as insígnias nefastas do tremendo Duque»:

"cui gloria magna lametem

Esset habere patrem, qui solo uicerat Afros

Nomine, et attonitas absens tremefecerat urbes:

Cuius in aduentu Zamor inclinata patentes

Obtulerat portas, non ausa uidere tremendi

Signa infesta Ducis."

O infante D. Duarte, amante suspiroso, é apoiado por Vénus que, tal como em Virgílio e em Camóes, visita Júpiter e que, com alguma chantagem bem humorada de permeio, lhe arranca a promessa de apresentar as núpcias. Vénus ameaça Júpiter com as habilidades de seu filho Cupido que, em ocasióes anteriores, já levara o pai dos deuses a metamorfosear-se no touro de Europa, na chuva de Dánae e no cisne de Leda.

Júpiter ri e dispóe-se a ceder, tanto mais que é esse também o desejo «de João, rei dos Lusíadas, a quem os Destinos são favoráveis» e a vontade de Teodósio, o duque de Bragança, irmão da noiva que é seguidamente elogiado.

A matéria épica aparece descrita nas tapeçarias que adornam o palácio dos duques de Bragança, em Vila Viçosa. Quase todos os episódios heróicos do Oriente são comuns aos Lusíadas: Duarte Pacheco em Cochim «agens raros lusíadas», comandando poucos portugueses, em luta com Samorim que foge, manchado de sangue (Lusiadas. X, 17); D. Francisco de Almeida na conquista de Granada e no Oriente, em Quíloa e Mombaça, sem esquecer a morte em Chaul, de seu filho, D. Lourenço de Almeida. A vingança de D. Francisco de Dabul e a sua grande vitória no mar em frente de Diu (Lusiadas. X, 26-36); Afonso de Albuquerque em Ormuz, Goa e Malaca (Lusíadas. $\mathrm{X}, 40-44)$.

Os deuses, disfarçados de homens, associam-se às festas no palácio ducal e pelas ruas de Vila Viçosa. Apenas o deus Apolo está ausente.

No carme LXIV de Catulo, nas núpcias de Tétis e Peleu, Apolo não comparece, por não querer honrar a festa com a sua presença. Nestas núpcias de Isabel e Duarte, Apolo não se mostra também, mas por um motivo plausível: «fazia construir então, nas margens do rio Mondego, edifícios grandiosos em honra das Musas, para bem dos Lusitanos e para renovar Atenas em favor do rei luso":

"nisi tunc ingentia Musis

Moenia iam Lysiis ad Mondae fluminis undam

Conderet, ut regi Lysio renouaret Athenas."

Depois do jantar nupcial, um outro vate Demódoco canta na lira andina ou virgiliana os primórdios dos reis dos Lusíadas (a palavra aparece repetidas vezes no 
poema), desde D. Afonso Henriques, sem esquecer o milagre de Ourique, até D. João III, ali presente. Um lugar de relevo é reservado a D. João I, antepassado dos noivos e pai do fundador da casa de Bragança. E Nun'Álvares Pereira não é omitido.

Ao enaltecer o rei Venturoso, um trecho é dedicado a Vasco da Gama e à descoberta do caminho marítimo para a Índia. E o vate termina o seu canto profético, prevendo o futuro brilhante no Norte de África (sempre a preocupação africana!) do futuro da casa de Bragança, chamado Duarte como o infante seu pai.

Infelizmente, as previsões dos poetas nem sempre se realizam e o futuro Bragança, que no canto de Vila Viçosa ocuparia o lugar de Aquiles no epitalâmio de Catulo, nasceu já depois da morte de seu pai, falecido jovem, e veio ele mesmo a finar-se antes de Alcácer-Quibir.

Uma das notas mais impressionantes deste poema, publicado vinte anos antes de Os Lusíadas, é o número de concordâncias virgilianas em que se encontram Manuel da Costa e Camóes, das quais, todavia, me náo ocuparei aqui.

\section{A tença de Camóes}

Ultimamente, alguma coisa se tem falado dos 15000 réis anuais da tença de Camóes. Um bom resumo da questão encontra-se num artigo saído no Correio da Manhã, jornal de Lisboa, nos seus números de 21 de Fevereiro e de 2 de Março de 1996. O autor é o Dr. Joaquim de Montezuma de Carvalho, advogado e escritor, que se ocupa sobretudo de questóes literárias e culturais.

A dificuldade maior - que já tem sido assinalada pelos que se preocuparam com a questâo - consiste em saber se os beneficiários dessas tenças viviam apenas da tença que nós conhecemos ou se a acumulavam com outras que desconhecemos ou com fontes de rendimento de que náo temos notícia.

Camóes parece ter vivido apenas da sua tença. Outro que parece ter vivido só de seu vencimento e, depois de aposentado, só da tença régia, foi o seu amigo André Falcão de Resende, juiz de fora de Torres Vedras e poeta.

Existe o documento da sua nomeação e respectivo ordenado concedido por D. Sebastiāo, a partir de 9 de Outubro de 1577, data do falecimento da Infanta D. Maria, irmá do rei D. João III, e portanto tia-avó de D. Sebastião.

A vila de Torres Vedras pertencia à Infanta e daí o teor do documento que vou transcrever: "Vedor de minha fazenda amigo ey por bẽ que o licenciado Andre Fallcão de Resende juiz de fora da villa de torres vedras tenha e aja de mantiméto e apousetaria có $o$ dito officio pera sj e seus equanto o servir conquoeta e ojto mil seiscentos e quarenta rs - scilicet - corenta mil rs. para seu mantimeto e doze mil rs pera mátimento de dous homes que o hão de companhar e có elle servir nas cousas de Justiça a rezáo de quinhentos rs por mz a cada hu e seis mil seiscentos e corente rs pera sua apousentarja de casas que tudo he outro tanto como tinha có dito offiçio a custa da Iffante dona maria, minha tia que santa gloria aja sendo ela uiua, pello que vos mando que lhes façais assentar os ditos conquoeta e ojto mil seiscentos e corenta rs no Liuro de minha fazenda e de noue dias do mez de outubro deste anno presente de bc lxxbjj é que a Iffante faleceo e diante Nos despacheis e 
façais pagar no allmoxarifado da villa dalanquer cô certidão dos vereadores da dita villa de torres vedras de como serue o dito offiçio cô os ditos dous homes e que se môtar dos ditos noue dias doutubro ate fim deste mes de dezembro the fareis paguar no dito allmoxarifado posto que ão fose na folha do asetameto se em bargo do Regimeto e contrario pedro da costa o fez e lixboa a xj de dezembro de ybclxxljj Jorge da Costa of fez escrever

concertada pedro castanho concertada

\section{Antonio daguiar» ${ }^{8}$}

Este documento dá-nos o ordenado do juiz de fora, 40000 réis anuais e o de cada um dos dois auxiliares, 6000 réis por ano, além de 6640 réis anuais para ajudas de custo de ambos, o que perfaz 3320 réis para cada um. Assim sendo, os dois funcionários de justiça ganhavam cada um o total de 9320 réis por ano.

Mais tarde, em 1595, já no reinado de Filipe II de Espanha, André Falcáo de Resende veio a aposentar-se com quarenta mil réis anuais que era o mesmo que ganhava, quando era juiz de fora. Sabemos o que ele pensava do seu ordenado, e da sua actividade profissional por uma carta que escreveu ao poeta Jerónimo Corte Real, cerca de 578:

"Que eu, por não mendicar, e lançar pedras

À gente, rendido à fortuna e fado,

Lides julgo e componho em Torres Vedras.

Mal respondido aqui, mal despachado,

Desvalido de amigos e senhores,

Remo já velho um remo tão pesado".

E mais adiante volta a falar de si próprio:

"Cançado, pobre, farto de desgosto,

Isto te escrevo ou sátira ou elegia,

Com puro amor e estilo mal composto."

Os 40000 réis anuais de André Falcáo não lhe traziam o sereno contentamento a que o seu natural de poeta horaciano o inclinava, mas enchiam-no de tristeza e frustração. Que devemos pensar dos 15000 réis de Camóes?

\section{Ilha dos Amores}

Como tentei mostrar num capítulo do meu livro Estudos Camonianos $^{9}$, a Ilha dos Amores é uma alegoria que corresponde em Camóes aos Campos Elísios da Eneida virgiliana. Não há, por isso, que situá-la no espaço.

\footnotetext{
${ }^{8}$ Américo da Costa Ramalho, Estudos sobre a Época do Renascimento, Coimbra, Centro de Estudos Clássicos e Humanísticos, 1969, pp. 259-260.

${ }^{9} 2^{\text {a }}$ edição, Lisboa, Instituto Nacional de Investigação Científica, 1980, pp. 73-81.
} 
Mas uma ilha existia, no percurso entre Goa ou Cochim e Lisboa, que aos olhos dos viajantes surgia como uma espécie de Ilha dos Amores camoniana. Era a única paragem, depois de meses de encarceramento nas cascas de noz que os conduziam, na sua maioria, em condiçôes extremamente precárias e de perigo constante.

Dei-me conta disso ao traduzir o De Missione Legatorum Iaponensium ad Romanam Curiam... Dialogus, ou seja, "Diálogos sobre a Missão dos Embaixadores Japoneses à Cúria Romana”, publicado pelo Padre Duarte de Sande, S.I., em Macau no ano de 1590 .

O roteiro do Pe. Sande é também uma história trágico-marítima. Para o jesuíta português, uma das maiores dívidas do Japão aos missionários jesuítas reside mesmo no facto de que, por amor a Deus e ao próximo, os apóstolos tenham consentido em realizar aquela viagem marítima de Lisboa ao Oriente.

Mas vamos à ilha, verdadeiro oásis num percurso infernal. Cito da minha tradução do Pe. Sande no "Colóquio Sexto", dedicado à "navegação da Índia para Portugal”. Fala Miguel, um dos interlocutores:

"MIGUEL - Nesta viagem marítima para Portugal não se toca porto algum, nem se vai a terra alguma, a não ser uma ilha que tem o nome de Santa Helena e está muito distante do Cabo da Boa Esperança na rota da linha equinocial. Deus, na sua infinita providência, colocou-a no meio do mar como oportuna estalagem para os que fazem esta navegação. Ai costumam os viajantes fazer aguada, refazer as forças e renovar as provisóes de carnes e frutos em abundância.» 10

E mais adiante continua: "A ilha é completamente deserta de homens, a não ser por ventura algum daqueles que outrora se chamavam anacoretas que, entretanto, ficando na ilha, leva uma vida solitária e nela cultiva (como muitas vezes acontece) aquilo de que os portugueses que ai chegam podem necessitar. A não ser, portanto, um ou dois que por vezes ai habitam, é proibido por ordem régia que mais residam nesta ilha. Com efeito, poucos bastam para a cultivar e promover a sua fertilidade. Na verdade, se os habitantes forem muitos, facilmente consumirão tudo o que nela nasce, por causa da exiguidade da sua superfície.

Mas pelo que toca ao que ai se produz: abunda sobretudo em águas perenes muito apropriadas para fazer a aguada, abunda em gado, principalmente miúdo, como cabras, em aves tanto domésticas, por exemplo galinhas, como selvagens, por exemplo, perdizes e outras semelhantes que, de inicio, ai deixadas pelos portugueses, deram a maior descendência, com a passagem do tempo. Abunda finalmente em muitos e suavissimos frutos de diversas árvores, tudo vitualhas de que os portugueses se servem com fartura, enquanto aí estão, $e$ delas transportam a maior carga para os navios, para relaxação e alimento dos corpos. Além das utilidades mencionadas, há também nesta ilha a grande comodidade da caça $e$ da pesca, com a qual não só se restabelecem os corpos, mas também se faz não pequena provisão de carnes salgadas para a alimentação na viagem.

10 "MICHAEL - In hac Lusitanica nauigatione nullus alius aditur portus, nulla que terra attingitur, nisi insula quaedam, quae a diua Helena nomen habet, et a promontorio bonae spei aequinoctii lineam uersus longe distat, quam in medio mari uelut opportunum quoddam illam nauigationem obeuntibus diuersorium Deus prouidentissimus constituit, ubi et aquari et uires reficere, et ex carnibus, fructibusque non paucis uictum instaurare uectores solent.» (p. 49). 
Nós, portanto, depois de usarmos todas as comodidades (56) e delícias desta amenissima ilha, durante onze dias, e de comprarmos não pequena quantidade de alimentos para $o$ restante tempo das navegaçóes, embarcámos de novo e no quarto dia antes dos Idos de Agosto (i.e. 10 de Agosto de 1584) sempre com os ventos a soprarem favoravelmente, chegámos ao desejadissimo porto de Lisboa.» ${ }^{11}$

A hipótese de identificação da Ilha dos Amores com Santa Helena não é nova. Encontra-se em João Soares de Brito no livro há pouco citado, e em Faria e Sousa, mas sem justificação convincente. Pela minha parte, não pretendi fazer essa identificação, mas apenas mostrar que, por detrás da alegoria, podia existir uma realidade factual.

Jan Huyghen van Linschotten, o famoso viajante holandês, observou que "os portugueses mostravam tanta alegria, ao navegar para o seu porto, como se estivessem entrando as portas do céu.» ${ }^{12}$

Quando Os Lusiadas foram publicados, Santa Helena estava prestes a acabar como base de apoio à navegação. Ia em breve tornar-se velhacouto de piratas ingleses e holandeses que aí aguardavam as naus portuguesas. Isso aconteceu sobretudo a partir de 1580, depois da perda da independência que nos identificou com os espanhóis com quem a Inglaterra e a Holanda estavam em guerra.

11 "MICHAEL - Insula est hominum habitatione omnino carens, nisi sit aliquis ex illis, qui olim anachoretae dicebantur, qui interdum in ea insula manens solitariam uitam agit, et ei talem adhibet culturam (ut saepe accidit) qualem Lusitanorum eo deuenientium necessitas postulat. Vno ergo, uel duobus ad summum exceptis, qui ibi aliquando manent, regio iussu prohibitum est, ne plures in ea insula commorentur: pauci namque sufficiunt, ut eam colant, fertilitatemque eius promoueant: plures uero si sint incolae, facile omnia, quae in ea nascuntur, consumentur, propter soli, ambituque exiguitatem. sed quod attinet ad ea, quae ibi proueniunt: abundat inprimis aquarum perennitate, ad aquationem ualde accomodata, abundat pecore praesertim minore, ut capris, deinde auibus, siue domesticis, ut gallinis, siue agrestibus, ut perdicibus, aliisque similibus, quae initio a Lusitanis ibi relictae maximum progressu temporis foetum ediderunt: abundat denique multis, suauissimisque diuersarum arborum fructibus, quibus omnibus rebus ad uictum pertinentibus, Lusitani quandiu ibi sunt, abundantissime utuntur, et maxima earum onera in naues comportant ad corporum relaxationem et alimentum. Vltra superiores utilitates est etiamin hac insula uenatus et piscatus magna commoditas, ex qua non solum corpora recreantur, uerum etiam carnibus salsis ad nauigationis uictum non mediocre fit incrementum. Non igitur his omnibus commodis, oblectamentisque 156/ huius amoenissimae insulae per undecim dies utentes, nec parum alimenti ad nauigationis reliquum tempus comparantes, nauemrursus conscendimus, et quarto idus Augusti secundissimis uentis semper spirantibus optatissimum Olysiponis portum tenuimus.» (pp. 55-56).

12 James Duffy, Shipwreck and Empire. Being an account of Portuguese maritime disasters in a century of decline. Harvard University Press, Cambridge, Mass., 1955, p. 97. 